\title{
Examining the complexity of functioning in persons with spinal cord injury attending first rehabilitation in Switzerland using structural equation modelling
}

This article has been corrected since Advance Online Publication and a correction is also printed in this issue

\author{
Jsabel Hodel $\mathbb{D}^{1,2} \cdot$ Cristina Ehrmann ${ }^{1,2} \cdot$ Gerold Stucki ${ }^{1,2} \cdot$ Jerome E. Bickenbach ${ }^{1,2}$. \\ Birgit Prodinger ${ }^{1,2,3} \cdot$ and the SwiSCI Study Group
}

Received: 27 August 2019 / Revised: 16 January 2020 / Accepted: 23 January 2020 / Published online: 13 February 2020

(c) The Author(s) 2020. This article is published with open access

\begin{abstract}
Study design Cross-sectional.

Objectives To examine the associations between activities, body structures and functions, and their relationship with aetiology, age and sex in persons with spinal cord injury (SCI) at discharge from first rehabilitation.

Setting Swiss SCI Cohort Study (SwiSCI).

Methods The study included 390 participants with newly acquired SCI and the International Classification of Functioning, Disability and Health (ICF) as conceptual frame of reference. Body structures were represented by injury level and severity; body functions by cardiovascular, pulmonary, skin, bowel and urinary functions and pain; mental functions by anxiety, depression, optimism and self-esteem; and activities by independence in performing activities of daily living (ADL). Using structural equation modelling (SEM), indirect effects of body structures and functions on independence in performing ADL through mental functions were tested for each mental function separately. For each structural model, fit was assessed using several indices and differences in aetiology, age and sex groups were explored.

Results The structural model about optimism showed good fit in all indices; the models about anxiety, depression and selfesteem showed conflicting fit indices, respectively. Within all models, effects on independence in performing ADL were mainly direct. Pain showed significant $(P<0.05)$ indirect effects on independence in performing ADL within the depression, optimism and self-esteem models. The model about anxiety showed differences in aetiology groups.

Conclusions Using an ICF-based modelling approach, this study presents an attempt towards a more comprehensive understanding of functioning in first rehabilitation of persons with SCI, which might be fundamental for rehabilitation planning.
\end{abstract}

Supplementary information The online version of this article (https:// doi.org/10.1038/s41393-020-0428-4) contains supplementary material, which is available to authorised users.

Jsabel Hodel

jsabel.hodel@paraplegie.ch

Swiss Paraplegic Research, Nottwil, Switzerland

2 Department of Health Sciences and Medicine, University of Lucerne, Lucerne, Switzerland

3 Faculty of Applied Health and Social Sciences, Technical University of Applied Sciences Rosenheim, Rosenheim, Germany

\section{Introduction}

The objective of rehabilitation is to optimise functioning for people, who because of a health condition, have difficulties carrying out activities of everyday life [1]. By 'functioning' we mean the key concept in the World Health Organization's International Classification of Functioning, Disability and Health (ICF) [2], namely the sum of human body structures and functions, as well as activities and areas of participation. As the ICF makes clear, rehabilitation's focus must be both on optimising functioning at the body level as well as the person's capacity to perform actions and to transform this improvement in capacity by making changes in the person's environment, to optimise their performance in everyday life. To achieve this, rehabilitation requires information on people's functioning to guide intervention 
planning and, more generally, decision-making among health professionals and patients.

Spinal cord injury (SCI) is a health condition that has devastating impacts on people's life and functioning. The injury creates impairments in body structures and functions, including the neurological damage of the spinal cord and the loss of motor, sensory and autonomic neurologic functions [3]. These impairments adversely affect the person's independence in performing daily activities such as self-care, mobility, bladder and bowel management. Newly injured persons in acute care and first rehabilitation not only have to undergo a traumatic event, they are also placed at risk of complications such as pressure injuries, thromboembolism, cardiopulmonary arrest, cardiovascular, pulmonary and renal conditions [4]. The degree to which rehabilitation can optimise their functioning will be influenced by injury-related factors such as the cause of the injury [5], as well as sociodemographic factors $[6,7]$. Factors such as depression have shown to influence functioning outcomes [8], however, how they impact the relationship between body structures and functions and activities and participation has not been examined yet. Given the wide and diverse range of impacts on body structures and functions, and resulting decrements in capacity to perform actions, $\mathrm{SCI}$ is associated with a high degree of complexity of people's functioning profile.

Deepening our understanding of this complexity, and in particular the associative linkages between health condition and components of functioning will be assisting in tailoring rehabilitation so as to meet the needs of people with SCI. Moreover, as countries put regulations in place that require an ICF-based documentation of assessment (as in Switzerland where ICF-based rehabilitation goals are required for quality assurance purposes [9]), empirical investigations into the associations described by the model of the ICF are important to ensure that evidence-based decisions can be made in rehabilitation practice.

To analyse these complex association structures, statistical modelling methods can be used [10]. In the SCI literature, we have found only a few studies that use these methods and the ICF model as a framework to analyse relationship structures among components of functioning [11] and interactions with the health condition and contextual factors [12-14].

Therefore, the objective of this study is to examine the associations between activities, body structures and functions, and their relationship with contextual factors in persons with SCI. Since the Swiss SCI Cohort Study (SwiSCI) [15] was developed based on the ICF as a conceptual model, the study provides an optimal basis for our purposes. Considering the variables available in SwiSCI, the specific aims are (1) to test indirect effects of body structures and functions on activities through different mental functions, and (2) to test the resulting models for differences in aetiology, age and sex groups. We use the notion 'indirect effects' to account for our cross-sectional study design; it should not be used synonymously with 'mediations', since the latter is referring to causal hypotheses requiring longitudinal study designs [16]. In this study, body structures were specified by injury level and severity; body functions by cardiovascular, pulmonary, skin, bowel and urinary functions and pain; mental functions by anxiety, depression, optimism and self-esteem; and activities by the independence in performing activities of daily living (ADL). See Table 1 for further information.

\section{Methods}

\section{Study design and participants}

This study used data from the SwiSCI Inception Cohort Study [15] in which newly injured persons with SCI are recruited during first rehabilitation in one of the four collaborating rehabilitation centres (SCI Center, Balgrist University Hospital, Zürich; Centre for SCI and Severe Head Injury, REHAB Basel, Basel; Clinique Romande de Réadaptation, Sion; Swiss Paraplegic Centre, Nottwil). Inclusion criteria of the SwiSCI Inception Cohort are the following: (1) age of 16 years or older, (2) permanent residence in Switzerland, (3) diagnosis of traumatic or non-traumatic SCI; exclusion criteria can be found elsewhere [15]. Measurements are performed one month (T1), three months (T2) and six months (T3) after SCI diagnosis during the clinical rehabilitation setting and at discharge (T4).

Until November 12th 2018, 883 participants were enroled in the SwiSCI Inception Cohort Study and completed data collection at discharge. For the purpose of this study, patients with the following characteristics were excluded from the sample in specific order: (1) death during first rehabilitation $(N=16)$, (2) no observations in all items of the independence in performing ADL measure at T4 $(N=174)$, (3) no observations in all items of the measures of the mental functions at T4 $(N=290)$, (4) intact neurological level or normal degree of impairment [17] at $\mathrm{T} 4(N=13)$.

\section{Measures}

The SwiSCI builds upon the ICF as conceptual foundation and during its development, instruments to operationalise the components of the ICF were identified [18, 19]. The ICF concepts reflected within the present study, measurement information, corresponding variables and response options are shown in Table 1. 


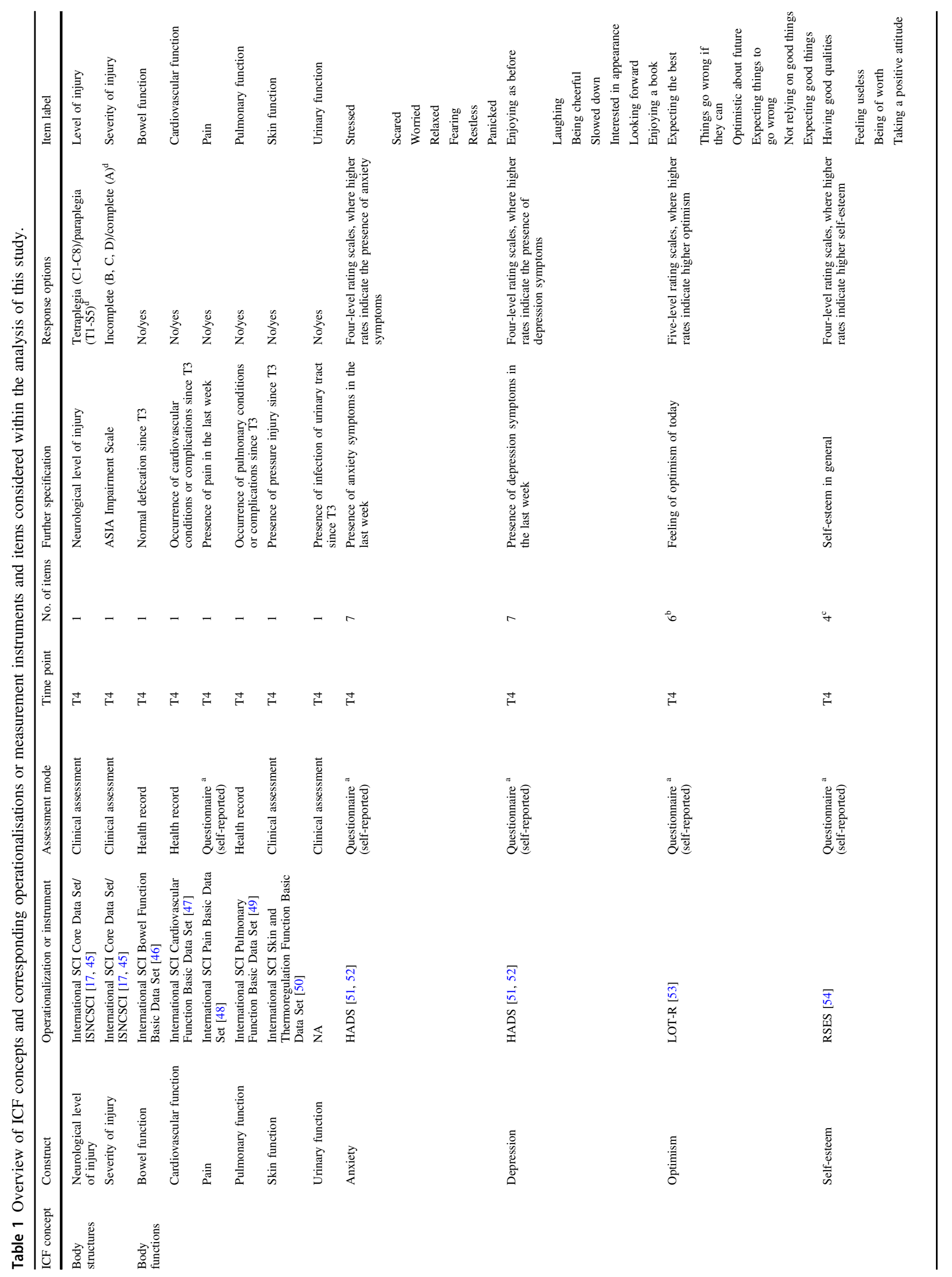




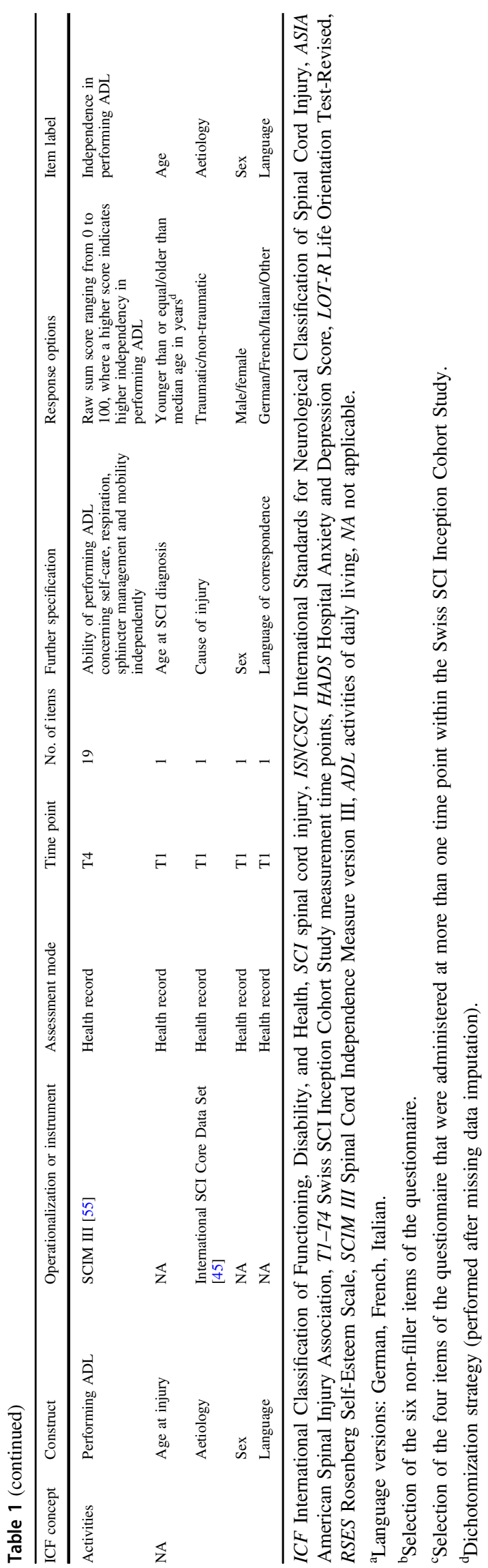

\section{Missing data imputation}

Observations in the response options 'unknown' or 'unable to determine' were considered as missing. Missing observations of the injury level or severity at T4 were replaced by the last observation of the corresponding variable at $\mathrm{T} 3$ or $\mathrm{T} 2$ or T1. Missing observations in the other variables were replaced by using the non-parametric random forest method MissForest [20] which is able to handle data with continuous as well as categorical variables. The MissForest method has been shown to not only outperform established methods such as nearest neighbour imputation and multivariate imputation by using chained equations [20,21], but also other random forest imputation methods [22]. See Supplementary Table 1 for further information on missing observations before data imputation.

\section{Rasch measurement model for the independence in performing ADL}

Using the Rasch measurement model [23, 24], the raw sum score of the Spinal Cord Independence Measure version III (SCIM III) was transformed to an interval sum score. Model fit was assessed by the individual and overall item fit, the person fit and the $P$ value of the $\chi^{2}$ test statistic of the item-trait interaction with good fit for non-significant $\chi^{2}(P>$ $0.05)$. Score reliability was tested by the person separation index (PSI) with an adequate expectation of 0.70 or above at the group level. To test whether the data fulfils the underlying model assumptions, local independency among items, unidimensionality of the score and the absence of differential item functioning (DIF) were tested iteratively. If items showed local dependence, a testlet approach was used to introduce super-items created by summing the initial response options of local dependent items. The corresponding analysis approach is described elsewhere [25].

\section{Measurement models for the mental functions}

We hypothesised each mental function to be a single latent factor represented by the respective observed questionnaire items (indicators) with uncorrelated measurement errors. In this context, direct effects of latent factors on indicators are referred to as factor loadings. Confirmatory factor analysis (CFA) $[16,26]$ was used to test if the hypothesised measurement models fit the data and hence, represent a single latent factor. Model fit was assessed by the following fit indices: $\chi^{2}$ test statistic, comparative fit index (CFI), root-mean-square error of approximation (RMSEA) and weighted-root-mean-square residuals (WRMR). The criteria to evaluate goodness of model fit were: non-significant $\chi^{2}$ $(P>0.05)$, CFI $>0.95$, RMSEA $<0.05$ and WRMR $<1.0$ [27]. If the initial CFA did not show good fit, the 
modification indices (MI) and residual correlation matrix of the respective measurement model were examined and indicator error correlations were introduced iteratively, (1) starting from the largest MI with significant Bonferroniadjusted $P$ value, and (2) starting from the largest absolute residual correlation $>0.10$ [16]. In the final measurement models, only significant indicator error correlations were retained.

For all measurement models, invariance was tested on the level of the significance pattern (configural invariance) and the estimates (weak invariance) of the factor loadings for aetiology, age, sex, level and severity of injury and language (German, French) groups as described by Hirschfeld and von Brachel [28].

\section{Structural models}

By using structural equation modelling (SEM) [16], indirect effects of body structures and functions on the independence in performing ADL through the mental functions anxiety, depression, optimism and self-esteem were tested for each mental function separately. Starting from the biopsychosocial model underlying the ICF, the following considerations guided the development of these hypotheses: first, we assumed the effects of body structures and functions on activities to be the primary or focal relationship within first rehabilitation of persons with SCI, and this relationship and patient's state of health to be most stable at the point of discharge. Therefore, we have applied data from discharge. Second, we considered anxiety, depression, optimism and self-esteem as mental functions belonging to the ICF component of body structures and functions. Since body structures and functions can be influenced by other body structures and functions, we hypothesised possible indirect effects of the other body structures and functions on activities through the mental functions. Third, any variables on environmental factors were not considered in this study since we draw upon data collected in first rehabilitation settings which we assumed to be not significantly different in their setup. Any differences would be a reflection of differences related to the rehabilitation setting rather than the person's environment. Fourth, any variables on participation in life of persons with SCI were not considered in this study since we assumed that a meaningful participation indicator requires a follow-up time after first rehabilitation.

For the SEM, the interval sum score of the SCIM III and the measurement models for the mental functions as resulted from the previous analyses were used. Model fit was assessed by the $\chi^{2}$ test statistic, the CFI and the WRMR. The following criteria were used to evaluate goodness of model fit: non-significant $\chi^{2}(P>0.05), \mathrm{CFI}>0.95$ and WRMR $<0.90$ [27].
Each structural model was explored for differences in aetiology, age and sex groups, provided that the measurement model for the corresponding mental function showed invariance for the respective group variable [29]. Whether a structural model shows differences in a specific group variable was assessed by comparing the $\chi^{2}$ test statistics between the corresponding freed structural model (allowing path parameters of the model to differ across respective groups) and the corresponding constrained structural model (restricting path parameters to be the same across respective groups).

The Rasch analyses were performed using RUMM2030 [30], other analyses were conducted by using $R$ 3.5.0 [31]. Imputation of missing observations was undertaken by the use of the package missForest 1.4 [20]. CFA and SEM were conducted by using the package lavaan 0.6-3 [32] and its weighted least squares mean- and variance-adjusted estimator able to compute robust standard errors of the model parameters and mean- and variance-adjusted test statistics. If not explicitly stated other, the significance level of $P$ values refers to 0.05 .

\section{Results}

In total, 390 participants were considered within this study. Sample descriptive information are presented in Table 2. Participants were mainly male $(69.49 \%)$ with incomplete (83.59\% after missing data imputation) paraplegia $(60.77 \%$ after missing data imputation). Mean age was 53.82 years (s.d. = 16.47) and median length of stay in first rehabilitation was 133.5 days $(25-75 \%$ percentiles $=75.25-192.5$ days). The observed variance-covariance matrix among the imputed model relevant variables is presented in Supplementary Table 2 .

\section{Rasch measurement model for the independence in performing ADL}

For the final model, two testlets were created: one testlet incorporated the items of the self-care subscale and the respiration and sphincter management subscale, the other testlet incorporated the items of the mobility subscale of the SCIM III. This testlet design showed good model fit with $\chi^{2}=18.28(\mathrm{df}=10, P=0.05)$ and PSI (with extremes) $=$ 0.92. Moreover, no DIF has been present for aetiology, age and sex.

\section{Measurement models for the mental functions}

None of the measurement models for the mental functions showed good fit in all indices in the initial CFA. The final model fit statistics after introducing indicator error correlations are reported in the following paragraph. 
Table 2 Characteristics of SwiSCI Inception Cohort Study participants and participants included within this study.

\begin{tabular}{|c|c|c|c|}
\hline Characteristics & $\begin{array}{l}\text { SwiSCI } \\
\text { Inception Cohort } \\
\text { Study }(N=883)\end{array}$ & $\begin{array}{l}\text { Present study } \\
\text { before missing } \\
\text { data imputation } \\
(N=390)\end{array}$ & $P$ value \\
\hline Sex & & & 0.43 \\
\hline Female $(\%)$ & $289(32.73)$ & $119(30.51)$ & \\
\hline Male $(\%)$ & $594(67.27)$ & $271(69.49)$ & \\
\hline Missing (\%) & $0(0)$ & $0(0)$ & \\
\hline $\begin{array}{l}\text { Mean age at SCI diagnosis, } \\
\text { years (s.d.) }\end{array}$ & $55.57(18.44)$ & $53.82(16.47)$ & $<0.05$ \\
\hline $\begin{array}{l}\text { Median age at SCI diagnosis, } \\
\text { years (1./3. quantiles) }\end{array}$ & $58(43 / 71)$ & $55(42 / 67)$ & \\
\hline $\begin{array}{l}\text { Younger than or equal } \\
\text { median age }(\%)\end{array}$ & $435(49.26)$ & $196(50.26)$ & \\
\hline Older than median age $(\%)$ & $448(50.74)$ & $194(49.74)$ & \\
\hline Missing (\%) & $0(0)$ & $0(0)$ & \\
\hline $\begin{array}{l}\text { Median length of stay, days } \\
\text { (1./3. quantiles) }\end{array}$ & $126(67 / 185.5)$ & $133.5(75.25 / 192.5)$ & 0.06 \\
\hline Missing (\%) & $0(0)$ & $0(0)$ & \\
\hline Language of correspondence & & & 0.99 \\
\hline German $(\%)$ & $678(76.78)$ & $299(76.67)$ & \\
\hline French $(\%)$ & $172(19.48)$ & $78(20.00)$ & \\
\hline Italian $(\%)$ & $23(2.60)$ & $11(2.82)$ & \\
\hline Other $(\%)$ & $3(0.34)$ & $2(0.51)$ & \\
\hline Missing (\%) & $7(0.79)$ & $0(0)$ & \\
\hline Aetiology & & & 0.47 \\
\hline Traumatic (\%) & $497(56.29)$ & $228(58.46)$ & \\
\hline Non-traumatic (\%) & $386(43.71)$ & $162(41.54)$ & \\
\hline Missing (\%) & $0(0)$ & $0(0)$ & \\
\hline Level of injury at discharge & & & $<0.001$ \\
\hline Tetraplegia (\%) & $271(30.69)$ & $152(38.97)$ & \\
\hline Paraplegia (\%) & $436(49.38)$ & $235(60.26)$ & \\
\hline Intact (\%) & $28(3.17)$ & $0(0)$ & \\
\hline Missing (\%) & $148(16.76)$ & $3(0.77)$ & \\
\hline Severity of injury at discharge & & & 0.22 \\
\hline Complete $(\%)$ & $140(15.86)$ & $63(16.15)$ & \\
\hline Incomplete $(\%)$ & $586(66.36)$ & $324(83.08)$ & \\
\hline Missing (\%) & 157 (17.78) & $3(0.77)$ & \\
\hline \multicolumn{3}{|c|}{ AIS-based neurological groups at discharge } & $<0.05$ \\
\hline C1-4 AIS A, B or C (\%) & $41(4.64)$ & $16(4.10)$ & \\
\hline C5-8 AIS A, B or C (\%) & $39(4.42)$ & $19(4.87)$ & \\
\hline T1-S5 AIS A, B or C (\%) & $162(18.35)$ & $80(20.51)$ & \\
\hline AIS D (\%) & $455(51.53)$ & $271(69.49)$ & \\
\hline AIS E $(\%)$ & $27(3.06)$ & $0(0)$ & \\
\hline Missing (\%) & $159(18.01)$ & $4(1.03)$ & \\
\hline
\end{tabular}

Distribution equality tests were performed using Pearson's $\chi^{2}$ test (without continuity correction) for categorical variables and Mann-Whitney test (without continuity correction) for continuous variables.

AIS American Spinal Injury Association Impairment Scale, SCI spinal cord injury, SwiSCI Swiss Spinal Cord Injury Cohort Study.

Anxiety: no indicator error correlations were introduced according to the pre-defined criteria. The initial CFA model was retained and showed good model fit in two of four indices with $\chi^{2}=33.328(\mathrm{df}=14, P=0.003), \mathrm{CFI}=0.992$, $\mathrm{RMSEA}=0.060, \mathrm{WRMR}=0.588$; depression: after introducing one indicator error correlation, the model showed good fit in two of four indices with $\chi^{2}=40.112(\mathrm{df}=13$, $P=0.000), \quad$ CFI $=0.990, \quad$ RMSEA $=0.073, \quad$ WRMR $=$ 0.661 ; optimism: after introducing four indicator error correlations, the final model showed good fit in all indices with $\chi^{2}=9.056(\mathrm{df}=5, P=0.107), \mathrm{CFI}=0.998, \mathrm{RMSEA}=$ 0.046, WRMR $=0.285$; self-esteem: after introducing one indicator error correlation, the model showed good fit in two of four indices with $\chi^{2}=6.961(\mathrm{df}=1, P=0.008)$, $\mathrm{CFI}=0.994, \mathrm{RMSEA}=0.124, \mathrm{WRMR}=0.417$.

The final measurement models for the mental functions including estimated factor loadings and indicator error correlations are shown in Supplementary Fig. 1. Model parameter estimates are presented completely standardised. Thus, the interpretation of the factor loadings is the following: given a change by one standard deviation unit in the latent factor, each factor loading estimates the corresponding amount of change in standard deviation units in the latent response variable assumed to underlie the respective observed indicator [16]. The factor loadings furthermore estimate the Pearson correlation between latent factor and respective latent response variable and their squares indicate the proportion of explained variance $\left(R^{2}\right)$ of the latent factor by the latent response variables [16].

The residual correlation matrices indicating the difference between observed and model-implied correlations for each final model are shown in the Supplementary Table 3.

The full results of the invariance tests of the measurement models can be found in Supplementary Table 4. Within this section we only present the results relevant for the subsequent group difference tests of the structural models. At the level of factor loading estimates, the anxiety and depression measurement models are both invariant for aetiology, age and sex groups, the optimism measurement model is invariant for age groups, and the self-esteem measurement model is invariant for age and sex groups.

\section{Structural models}

The model fit statistics of the hypothesised structural models are reported in the following paragraph.

Anxiety: the model showed good fit in two of three indices with $\chi^{2}=120.030(\mathrm{df}=82, P=0.004), \mathrm{CFI}=$ 0.983 , WRMR $=0.811$; depression: the model showed good fit in two of three indices with $\chi^{2}=107.704(\mathrm{df}=81$, $P=0.025), \mathrm{CFI}=0.990, \mathrm{WRMR}=0.770$; optimism: the model showed overall good fit with $\chi^{2}=60.360(\mathrm{df}=62$, $P=0.535), \mathrm{CFI}=1.000, \mathrm{WRMR}=0.588$; self-esteem: the model showed good fit in two of three indices with $\chi^{2}=$ $67.077(\mathrm{df}=36, \quad P=0.001), \quad \mathrm{CFI}=0.971, \quad \mathrm{WRMR}=$ 0.825 . The residual correlation matrices for each model are shown in the Supplementary Table 5.

The structural models and completely standardised parameter estimates are shown in Fig. 1a-d. The interpretation of 
a

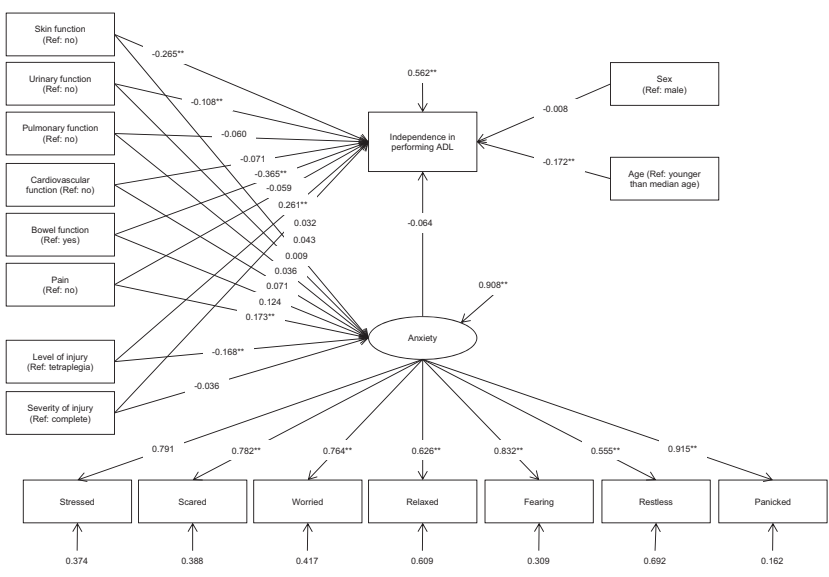

C

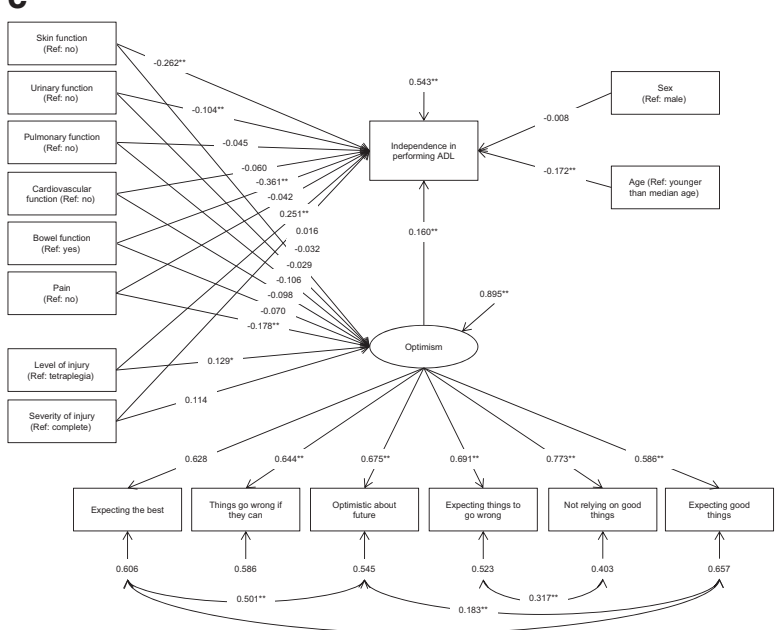

Fig. 1 Structural models showing the relationships of body structures and functions with activities of daily living. a Completely standardised parameter estimates of the structural model about anxiety $(N=390)$. b Completely standardised parameter estimates of the structural model about depression $(N=390)$. c Completely standardised parameter estimates of the structural model about optimism $(N=390)$. d Completely standardised parameter estimates of the structural model about self-esteem $(N=390)$. $A D L$ activities of daily

factor loadings is the same as already described in the previous section; the interpretation of the other path coefficients is analogous to the interpretation of coefficients in a multiple regression: given a change of one standard deviation unit in the independent variable, the path coefficient estimates the corresponding change in standard deviation units in the dependent variable, holding all other respective independent variables constant. Fig. 1c for example indicates that the presence of a pressure injury (skin function, response option yes) is associated with lower independence in performing ADL (path coefficient $\beta=-0.262, P<0.01$ ) and lower optimism $(\beta=-0.032)$; whereas a lower level of injury (paraplegia) is associated with higher independence in performing $\operatorname{ADL}(\beta=0.251, P<0.01)$ and higher optimism b

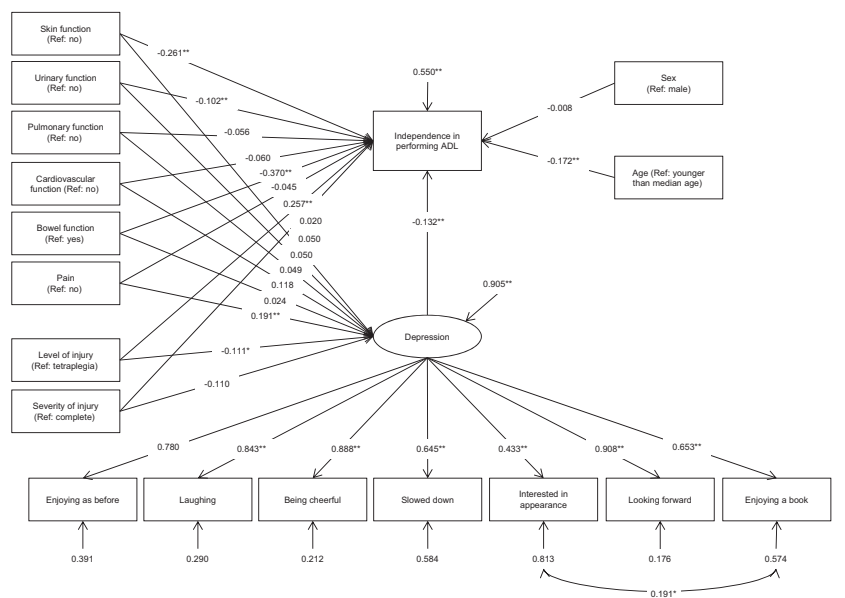

d

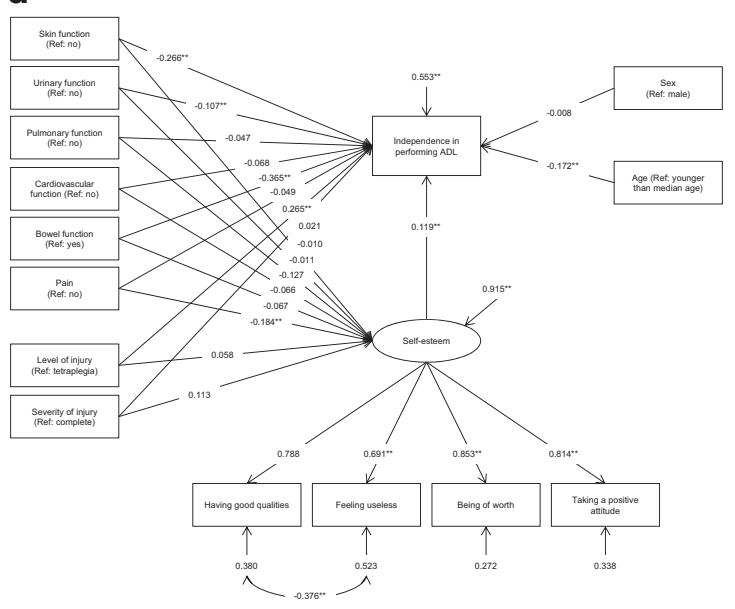

living, Ref reference response option of binary variables. Squares indicate observable variables including the independence in performing activities of daily living (ADL) specified by the interval sum score of the Spinal Cord Independence Measure version III (SCIM III); ellipses indicate latent factors; single-headed arrows indicate direct effects including measurement errors; double-headed arrows indicate correlations; correlations among and measurement errors of independent observable variables are omitted; $* P<0.05$; $* * P<0.01$.

$(\beta=0.129, P<0.05)$; and higher optimism is associated with higher independence in performing ADL $(\beta=0.160, P<$ 0.01 ). When looking at the squared factor loadings in this model, we see that the latent response variables represented by the indicator variables show proportions of explained variance of the latent factor optimism between 0.34 ('expecting good things') and 0.60 ('not relying on good things').

The respective model estimates for the indirect and total (direct plus indirect) effects of body structures and functions on the independence in performing ADL for the four structural models are shown in Table 3. Within all structural models, effects on independence in performing ADL were mainly direct with significant positive effects of a lower 
Table 3 Completely standardised estimates for the indirect and total effects of body structures and functions on the independence in performing activities of daily living for the structural models about anxiety, depression, optimism and selfesteem.

\begin{tabular}{lccccc}
\hline ICF concept and variable & \multicolumn{2}{l}{ Indirect effects through: } & Total effects \\
\cline { 2 - 5 } & Anxiety & Depression & Optimism & Self-esteem & \\
\hline Body functions & & & & & \\
$\quad$ Bowel function (Ref: yes) & -0.008 & -0.003 & -0.011 & -0.008 & $-0.373^{* *}$ \\
Cardiovascular function (Ref: no) & -0.005 & -0.016 & -0.016 & -0.008 & -0.076 \\
Pain (Ref: no) & -0.011 & $-0.025^{*}$ & $-0.029^{*}$ & $-0.022^{*}$ & -0.070 \\
Pulmonary function (Ref: no) & -0.002 & -0.006 & -0.017 & -0.015 & -0.062 \\
$\quad$ Skin function (Ref: no) & -0.003 & -0.007 & -0.005 & -0.001 & $-0.267^{* *}$ \\
$\quad$ Urinary function (Ref: no) & -0.001 & -0.007 & -0.005 & -0.001 & $-0.109^{* *}$ \\
Body structures & & & & & $0.272^{* *}$ \\
$\quad$ Level of injury (Ref: tetraplegia) & 0.011 & 0.015 & 0.021 & 0.007 & 0.035 \\
\hline Severity of injury (Ref: complete) & 0.002 & 0.015 & 0.018 & 0.013 & \\
\hline
\end{tabular}

The total effects are the same for all structural models.

Ref reference response option of binary variables.

$* P<0.05 ; * * P<0.01$ level of injury and significant negative effects of occurring complications or conditions in urinary, bowel and skin functions. Significant indirect effects were found for pain within the structural models about depression, optimism and self-esteem, respectively.

Table 4 shows the results of the structural model group difference tests. Significant group differences were found in aetiology groups for the structural model about anxiety.

\section{Discussion}

Using SEM to examine the possible influence of mental functions within the relationship of body structures, body functions and activities, pain showed significant indirect effects on the independence in performing activities of ADL in the structural models about depression, optimism and self-esteem. Group differences were found in aetiology groups for the structural model about anxiety.

However, the results need to be interpreted within its conceptual framework and the cross-sectional design of the study: first, personal factors are not classified yet in the ICF and there remains to be a debate about their definition and relationship to mental functions [33]. Regardless whether you consider anxiety, depression, optimism and self-esteem as mental functions or personal factors, they are important when looking at peoples' functioning. Second, this study reflects an attempt towards generating empirical evidence for a comprehensive understanding of functioning in first rehabilitation of persons with SCI as it is shown in the ICF. In this understanding, it can serve as a starting point for further model development and analyses. Since pain is the only body function that showed indirect effects on independence in performing ADL in the structural models about depression, optimism and self-esteem, it could be worthwhile to reconsider the relationship of pain and these mental functions in more detail and together with other pain items, e.g. clinical pain records.

The community survey of SwiSCI revealed that pain is highly prevalent in persons with SCI living in the community (with musculoskeletal type of pain most frequently reported) [34] and is perceived as one of the most important problems in functioning following SCI [35]. However, the relationships among pain, mental functions and independence in performing ADL appear to be complex, as for example literature about the pain-depression relationship often reflects both directions: in the general population, pain and depression symptoms are found to be commonly occurring and their relationship seem to be bidirectional [36]. Moreover, the bidirectional associations between depressive symptoms and pain seem to be similar for people with functioning problems and those without [37]. In the SCI community setting, increased pain was found to be a risk factor for developing of depression [38]. Moreover, chronic pain is suggested to be associated with increased depressive symptom levels and less participation [39], and with negative effects on psychological functioning, social integration and activities including mobility, self-care, social and recreational activities [40]. On the other hand, a meta-analysis of possible determinants for pain in persons with SCI has shown that depression prevalence is associated with pain prevalence [41]. Within the acute SCI setting, the pain-depression interaction remains unclear; different models have been tested and are conceivable [42], other studies have found that depressive symptoms are not related to pain or functional impairment [43]. Therefore, further research is needed to uncover comprehensive interactions among mental functions, possible changes in mental functions over time, and their associations with other body functions, body structures, activities and participation [44]. 
Table 4 Group difference tests of the structural models for aetiology, age and sex groups.

\begin{tabular}{llll}
\hline $\begin{array}{l}\text { Structural model and } \\
\text { parameter constrains }\end{array}$ & $\chi_{\mathrm{M}}^{2}$ & $\mathrm{df}_{\mathrm{M}}$ & $\begin{array}{l}\text { Model } \\
\text { comparison }\end{array}$ \\
\hline & & $\chi_{\mathrm{D}}^{2} \mathrm{df}_{\mathrm{D}}$ \\
\hline
\end{tabular}

\section{Aetiology}

Anxiety

Freed

Constrained

134.939

164

Depression

Freed

Constrained

207.347

183

$31.157 *$

19

Optimism

Freed

Constrained

Self-esteem

Freed

Constrained

Age

Anxiety

Freed

Constrained

133.634

150

Depression

Freed

Constrained

130.289

162

172.903

181

20.509

Optimism

Freed

Constrained

188.145

168

$113.641 \quad 148$

$140.591 \quad 166$

13.927

18

$72.815 \quad 112$

$112.368 \quad 130$

20.790

Self-esteem

Freed

Constrained

64.630

89.555

64

82

15.876

18

Sex

Anxiety

Freed

96.295

150
Constrained

Depression

Freed

Constrained

$100.820 \quad 148$

$126.733 \quad 166$

$15.230 \quad 18$

$15.230 \quad 18$

Optimism

Freed

Constrained

Self-esteem

Freed

Constrained

53.255

107.167

$16.770 \quad 18$

-

Freed, no constrains on parameter estimates across respective groups; Constrained, all path estimates constrained to be equal across respective groups. $M$ model, $D$ difference.

${ }^{*} P<0.05$.

\section{Limitations}

We note several methodological limitations to our study. First, the three measurement models for anxiety, depression and self-esteem are lacking good fit in terms of the $P$ value of the $\chi^{2}$ test statistic which is leading to unknown bias in the corresponding structural models, which likewise are lacking good fit in this index. Second, since the measurement models for the mental functions were modified in an exploratory and data-driven way by introducing indicator error correlations based on MI and residual correlation matrices, the results of this study are not generalisable and should be cross-validated. Moreover, indicator error correlations can be viewed as shared variance besides the common latent factor and the measurement models become multidimensional by their introduction. Third, we might not be able to detect invariances within our measurement models or group differences within our structural models due to the small sample sizes of some groups tested. Fourth, a selection bias on the sample used in this analysis could have occurred since (1) the filling in of the questionnaires within the SwiSCI Inception Cohort Study is optional and (2) we excluded participants with no observations in the ADL and the mental functions variables. Fifth, the crosssectional design of the study does not allow for causal conclusions. Thus, a longitudinal study design is needed to clarify and extend the presented structural models.

\section{Conclusion}

Using an ICF-based modelling approach, this study presents an attempt towards a more comprehensive understanding of functioning in first rehabilitation of persons with SCI, which might be fundamental for rehabilitation planning and decision-making among health professionals and patients.

\section{Data availability}

The datasets generated and analysed during this study are not publicly available due to the commitment of SwiSCI to protect participants' privacy but are available at the SwiSCI Study Center (swisci.research@paraplegie.ch) on reasonable request.

Acknowledgements The authors would like to thank Alan Tennant and Anke Scheel-Sailer for the valuable advices on the methodology and study conceptualisation, and the informative discussions about the interpretation of the results. The members of the SwiSCI Steering Committee are: Xavier Jordan, Fabienne Reynard (Clinique Romande de Réadaptation, Sion); Michael Baumberger, Hans Peter Gmünder (Swiss Paraplegic Centre, Nottwil); Armin Curt, Martin Schubert (University Clinic Balgrist, Zürich); Margret Hund-Georgiadis, Kerstin 
Hug (REHAB Basel, Basel); Urs Styger (Swiss Paraplegic Association, Nottwil); Daniel Joggi (Swiss Paraplegic Foundation, Nottwil); NN (Representative of persons with SCI); Nadja Münzel (Parahelp, Nottwil); Mirjam Brach, Gerold Stucki (Swiss Paraplegic Research, Nottwil); Armin Gemperli (SwiSCI Coordination Group at Swiss Paraplegic Research, Nottwil). This study is part of the cumulative dissertation of Jsabel Hodel.

Funding This study is part of the project 'Enhancing continuous quality improvement and supported clinical decision making by standardized reporting of functioning' within the National Research Programme 'Smarter Health Care' (NRP74) funded by the Swiss National Science Foundation.

Author contributions $\mathrm{JH}$ contributed to the study design, conducted the analyses, interpreted the results and drafted the manuscript. CE contributed to the study design, conducted and supervised the analysis and interpreted the results. GS and JEB contributed to the study conceptualisation. BP contributed to the study design, supervised the analysis and drafting of the manuscript and interpreted the results. All authors revised earlier versions of the manuscript, approved the final version and agreed to be accountable for all aspects of the work in ensuring that questions related to the accuracy or integrity of any part of the work are appropriately investigated and resolved.

\section{Compliance with ethical standards}

Conflict of interest The authors declare that they have no conflict of interest.

Ethics statement The SwiSCI was approved by the responsible ethics committees of the cantons of Lucerne, Zurich, Basel-Stadt and Valais.

Publisher's note Springer Nature remains neutral with regard to jurisdictional claims in published maps and institutional affiliations.

Open Access This article is licensed under a Creative Commons Attribution 4.0 International License, which permits use, sharing, adaptation, distribution and reproduction in any medium or format, as long as you give appropriate credit to the original author(s) and the source, provide a link to the Creative Commons license, and indicate if changes were made. The images or other third party material in this article are included in the article's Creative Commons license, unless indicated otherwise in a credit line to the material. If material is not included in the article's Creative Commons license and your intended use is not permitted by statutory regulation or exceeds the permitted use, you will need to obtain permission directly from the copyright holder. To view a copy of this license, visit http://creativecommons. org/licenses/by/4.0/.

\section{References}

1. Meyer T, Gutenbrunner C, Bickenbach J, Cieza A, Melvin J, Stucki G. Towards a conceptual description of rehabilitation as a health strategy. J Rehabil Med. 2011;43:765-9.

2. World Health Organization. International Classification of Functioning, disability and health: ICF. Geneva: World Health Organization; 2001.

3. World Health Organization, International Spinal Cord Society. International Perspectives on Spinal Cord Injury. Geneva: World Health Organization; 2013.

4. Chen D, Apple DF Jr., Hudson LM, Bode R. Medical complications during acute rehabilitation following spinal cord injury-current experience of the model systems. Arch Phys Med Rehabil. 1999; 80:1397-401

5. Celani MG, Spizzichino L, Ricci S, Zampolini M, Franceschini M. Spinal cord injury in Italy: a multicenter retrospective study. Arch Phys Med Rehabil. 2001;82:589-96.

6. Sipski ML, Jackson AB, Gómez-Marín O, Estores I, Stein A. Effects of gender on neurologic and functional recovery after spinal cord injury. Arch Phys Med Rehabil. 2004;85:1826-36.

7. Teeter L, Gassaway J, Taylor S, LaBarbera J, McDowell S, Backus D, et al. Relationship of physical therapy inpatient rehabilitation interventions and patient characteristics to outcomes following spinal cord injury: the SCIRehab project. J Spinal Cord Med. 2012;35:503-26.

8. Geyh S, Kunz S, Müller R, Peter C. Describing functioning and health after spinal cord injury in the light of psychologicalpersonal factors. J Rehabil Med. 2016;48:219-34.

9. ANQ Nationaler Verein für Qualitätsentwicklung in Spitälern und Kliniken. Review information: rehabilitation. Available from: https://www.anq.ch/en/departments/rehabilitation/. Accessed 05 June 2019.

10. Greenland S, Brumback B. An overview of relations among causal modelling methods. Int J Epidemiol. 2002;31:1030-7.

11. Ehrmann C, Prodinger B, Gmunder HP, Hug K, Bickenbach JE, Stucki G. Describing functioning in people living with spinal cord injury in Switzerland: a graphical modeling approach. Arch Phys Med Rehabil. 2018;99:1965-81.

12. van Leeuwen CM, Post MW, Westers P, van der Woude LH, de Groot S, Sluis T, et al. Relationships between activities, participation, personal factors, mental health, and life satisfaction in persons with spinal cord injury. Arch Phys Med Rehabil. 2012; 93:82-89.

13. Rivers CS, Fallah N, Noonan VK, Whitehurst DG, Schwartz CE, Finkelstein JA, et al. Health conditions: effect on function, healthrelated quality of life, and life satisfaction after traumatic spinal cord injury. A Prospective Observational Registry Cohort Study. Arch Phys Med Rehabil. 2018;99:443-51.

14. Reinhardt JD, Mansmann U, Fellinghauer BA, Strobl R, Grill E, von Elm E, et al. Functioning and disability in people living with spinal cord injury in high- and low-resourced countries: a comparative analysis of 14 countries. Int J Public Health. 2011; $56: 341-52$.

15. Post MWM, Brinkhof MWG, von Elm E, Boldt C, Brach M, Fekete C, et al. Design of the Swiss Spinal Cord Injury Cohort Study. Am J Phys Med Rehabil. 2011;90:5-16.

16. Kline RB. Principles and practice of structural equation modeling. 4th ed. New York: Guilford Press; 2016.

17. Kirshblum SC, Burns SP, Biering-Sorensen F, Donovan W, Graves DE, Jha A, et al. International standards for neurological classification of spinal cord injury (revised 2011). J Spinal Cord Med. 2011;34:535-46.

18. Cieza A, Boldt C, Ballert CS, Eriks-Hoogland I, Bickenbach JE, Stucki G. Setting up a cohort study on functioning: deciding what to measure. Am J Phys Med Rehabil. 2011;90:17-28.

19. Fekete C, Boldt C, Post M, Eriks-Hoogland I, Cieza A, Stucki G. How to measure what matters: development and application of guiding principles to select measurement instruments in an epidemiologic study on functioning. Am J Phys Med Rehabil. 2011;90:29-38.

20. Stekhoven DJ, Bühlmann P. MissForest—non-parametric missing value imputation for mixed-type data. Bioinformatics. 2012;28: $112-8$.

21. Waljee AK, Mukherjee A, Singal AG, Zhang Y, Warren J, Balis $\mathrm{U}$, et al. Comparison of imputation methods for missing laboratory data in medicine. BMJ Open. 2013;3:e002847.

22. Tang F, Ishwaran H. Random forest missing data algorithms. Stat Anal data Min. 2017;10:363-77. 
23. Andrich D. Rating scales and Rasch measurement. Expert Rev Pharmacoecon Outcomes Res. 2011;11:571-85.

24. Tennant A, Conaghan PG. The Rasch measurement model in rheumatology: what is it and why use it? When should it be applied, and what should one look for in a Rasch paper? Arthritis Rheum. 2007;57:1358-62.

25. Maritz R, Tennant A, Fellinghauer C, Stucki G, Prodinger B. The functional independence measure 18 -item version can be reported as a unidimensional interval-scaled metric: internal construct validity revisited. J Rehabil Med. 2019;51:193-200.

26. Brown TA. Confirmatory factor analysis for applied research New York: Guilford Press; 2006.

27. Yu C-Y. Evaluating cutoff criteria of model fit indices for latent variable models with binary and continuous outcomes. Unpublished doctoral dissertation. Los Angeles: University of California; 2002.

28. Hirschfeld G, von Brachel R. Multi-group confirmtory factor analysis in $\mathrm{R}-\mathrm{a}$ tutorial in measurement invariance with continuous and ordinal indicators. Pract Assess Res Eval. 2014;19:1-12.

29. Hsiao Y-Y, Lai MHC. The impact of partial measurement invariance on testing moderation for single and multi-level data. Front Psychol. 2018;9:740.

30. Andrich D, Sheridan BS, Luo G. RUMM2030: an MS Windows computer program for the analysis of data according to Rasch unidimensional models for measurement. Perth, Western Australia: RUMM Laboratory; 2015.

31. $\mathrm{R}$ Core Team. $\mathrm{R}$ : a language and environment for statistical computing. Vienna, Austria: R Foundation for Statistical Computing; 2018. https://www.R-project.org/.

32. Rosseel Y. lavaan: an R Package for structural equation modeling. J Stat Softw. 2012;48:1-36.

33. Heerkens YF, de Weerd M, Huber M, de Brouwer CPM, van der Veen S, Perenboom RJM, et al. Reconsideration of the scheme of the international classification of functioning, disability and health: incentives from the Netherlands for a global debate. Disabil Rehabil. 2018;40:603-11.

34. Müller R, Brinkhof MW, Arnet U, Hinrichs T, Landmann G, Jordan X, et al. Prevalence and associated factors of pain in the Swiss spinal cord injury population. Spinal Cord. 2017;55: 346-54.

35. Rubinelli S, Glassel A, Brach M. From the person's perspective: perceived problems in functioning among individuals with spinal cord injury in Switzerland. J Rehabil Med. 2016;48:235-43.

36. Bair MJ, Robinson RL, Katon W, Kroenke K. Depression and pain comorbidity: a literature review. Arch Intern Med. 2003;163: 2433-45.

37. Gayman MD, Brown RL, Cui M. Depressive symptoms and bodily pain: the role of physical disability and social stress. Stress Health. 2011;27:52-53.

38. Hoffman JM, Bombardier CH, Graves DE, Kalpakjian CZ, Krause JS. A longitudinal study of depression from 1 to 5 years after spinal cord injury. Arch Phys Med Rehabil. 2011;92:411-8.
39. Müller R, Landmann G, Bechir M, Hinrichs T, Arnet U, Jordan X, et al. Chronic pain, depression and quality of life in individuals with spinal cord injury: Mediating role of participation. J Rehabil Med. 2017;49:489-96.

40. Jensen MP, Hoffman AJ, Cardenas DD. Chronic pain in individuals with spinal cord injury: a survey and longitudinal study. Spinal Cord. 2005;43:704-12.

41. van Gorp S, Kessels AG, Joosten EA, van Kleef M, Patijn J. Pain prevalence and its determinants after spinal cord injury: a systematic review. Eur J Pain. 2015;19:5-14.

42. Cairns DM, Adkins RH, Scott MD. Pain and depression in acute traumatic spinal cord injury: origins of chronic problematic pain? Arch Phys Med Rehabil. 1996;77:329-35.

43. Hassanpour K, Hotz-Boendermaker S, Dokladal P, Curt A. Low depressive symptoms in acute spinal cord injury compared to other neurological disorders. J Neurol. 2012;259:1142-50.

44. Peter C, Müller R, Cieza A, Geyh S. Psychological resources in spinal cord injury: a systematic literature review. Spinal Cord. 2012;50:188-201.

45. DeVivo M, Biering-Sorensen F, Charlifue S, Noonan V, Post M, Stripling $\mathrm{T}$, et al. International spinal cord injury core data set. Spinal Cord. 2006;44:535-40.

46. Krogh K, Perkash I, Stiens SA, Biering-Sorensen F. International bowel function basic spinal cord injury data set. Spinal Cord. 2009;47:230-4.

47. Krassioukov A, Alexander MS, Karlsson AK, Donovan W, Mathias CJ, Biering-Sorensen F. International spinal cord injury cardiovascular function basic data set. Spinal Cord. 2010;48: 586-90.

48. Widerstrom-Noga E, Biering-Sorensen F, Bryce T, Cardenas DD, Finnerup NB, Jensen MP, et al. The international spinal cord injury pain basic data set. Spinal Cord. 2008;46:818-23.

49. Biering-Sorensen F, Krassioukov A, Alexander MS, Donovan W, Karlsson AK, Mueller G, et al. International spinal cord injury pulmonary function basic data set. Spinal Cord. 2012;50:418-21.

50. Karlsson AK, Krassioukov A, Alexander MS, Donovan W, Biering-Sorensen F. International spinal cord injury skin and thermoregulation function basic data set. Spinal Cord. 2012;50: $512-6$.

51. Zigmond AS, Snaith RP. The hospital anxiety and depression scale. Acta Psychiatr Scand. 1983;67:361-70.

52. Snaith RP, Zigmond AS. The hospital anxiety and depression scale. Br Med J (Clin Res Ed). 1986;292:344.

53. Herzberg PY, Glaesmer H, Hoyer J. Separating optimism and pessimism: a robust psychometric analysis of the revised Life Orientation Test (LOT-R). Psychol Assess. 2006;18:433-8.

54. Rosenberg M. Society and the adolescent self-image. Princeton, N. J.: Princeton University Press; 1965.

55. Itzkovich M, Gelernter I, Biering-Sorensen F, Weeks C, Laramee MT, Craven BC, et al. The spinal cord independence measure (SCIM) version III: reliability and validity in a multi-center international study. Disabil Rehabil. 2007;29:1926-33. 